\title{
COMPARISON OF PORE FRACTAL CHARACTERISTICS BETWEEN MARINE AND CONTINENTAL SHALES
}

\author{
JUN LIU,,,,$+ \ddagger$ YANBIN YAO,,,,+ DAMENG LIU, ${ }^{*}$ YIDONG CAI* \\ and JIANCHAO $\mathrm{CAI}^{\S}$ \\ ${ }^{*}$ School of Energy Resource, China University of Geosciences (Beijing) \\ Beijing 100083, P. R. China \\ ${ }^{\dagger}$ Coal Reservoir Laboratory of National Engineering Research Center \\ of CBM Development \& Utilization, China University of Geosciences \\ Beijing 100083, P. R. China \\ ${ }^{\ddagger}$ Beijing Key Laboratory of Unconventional Natural Gas Geological Evaluation \\ and Development Engineering, Beijing 100083, P. R. China \\ $\S_{H}$ ubei Subsurface Multi-scale Imaging Key Laboratory \\ Institute of Geophysics and Geomatics, China University of Geosciences \\ Wuhan 4300\%4, P. R. China \\ 『yyb@cugb.edu.cn
}

Received December 6, 2017

Accepted January 19, 2018

Published March 7, 2018

\begin{abstract}
Fractal characterization offers a quantitative evaluation on the heterogeneity of pore structure which greatly affects gas adsorption and transportation in shales. To compare the fractal characteristics between marine and continental shales, nine samples from the Lower Silurian Longmaxi formation in the Sichuan basin and nine from the Middle Jurassic Dameigou formation in the Qaidam basin were collected. Reservoir properties and fractal dimensions were characterized for all the collected samples. In this study, fractal dimensions were originated
\end{abstract}

\footnotetext{
"Corresponding author.

This is an Open Access article published by World Scientific Publishing Company. It is distributed under the terms of the Creative Commons Attribution 4.0 (CC-BY) License. Further distribution of this work is permitted, provided the original work is properly cited.
} 
from the Frenkel-Halsey-Hill (FHH) model with $\mathrm{N}_{2}$ adsorption data. Compared to continental shale, marine shale has greater values of quartz content, porosity, specific surface area and total pore volume but lower level of clay minerals content, permeability, average pore diameter and methane adsorption capacity. The quartz in marine shale is mostly associated with biogenic origin, while that in continental shale is mainly due to terrigenous debris. The $\mathrm{N}_{2}$ adsorption-desorption isotherms exhibit that marine shale has fewer inkbottle-shaped pores but more plate-like and slit-shaped pores than continental shale. Two fractal dimensions $\left(D_{1}\right.$ and $D_{2}$ ) were obtained at $P / P_{o}$ of $0-0.5$ and $0.5-1$. The dimension $D_{2}$ is commonly greater than $D_{1}$, suggesting that larger pores (diameter $>\sim 4 \mathrm{~nm}$ ) have more complex structures than small pores (diameter $<\sim 4 \mathrm{~nm}$ ). The fractal dimensions (both $D_{1}$ and $D_{2}$ ) positively correlate to clay minerals content, specific surface area and methane adsorption capacity, but have negative relationships with porosity, permeability and average pore diameter. The fractal dimensions increase proportionally with the increasing quartz content in marine shale but have no obvious correlation with that in continental shale. The dimension $D_{1}$ is correlative to the TOC content and permeability of marine shale at a similar degree with dimension $D_{2}$, while the dimension $D_{1}$ is more sensitive to those of continental shale than dimension $D_{2}$. Compared with dimension $D_{2}$, for two shales, dimension $D_{1}$ is better associated with the content of clay minerals but has worse correlations with the specific surface area and average pore diameter.

Keywords: Marine Shale; Continental Shale; Nitrogen Gas Adsorption-Desorption; Fractal Dimension; Methane Adsorption.

\section{INTRODUCTION}

Shale reservoir is referred to as a complicated porous material which contains complex and heterogeneous pore structure with both matrix pores and fracture networks. ${ }^{12}$ Pore structures are usually characterized by pore size, shape, volume, surface area and spatial distribution. All these features have a significant impact on gas enrichment and seepage in shale. ${ }^{3}$ Therefore, investigating the shale pore structure is of practical significance for evaluating the gas storage capacity and gas flow mechanisms in shale reservoirs. ${ }^{4}$ For this reason, considerable efforts are expected to improve the understanding of pore structures in shale. $\frac{516}{}$ Various techniques such as high-pressure mercury injection porosimetry (MIP), quantitative X-ray CT imaging, nuclear magnetic resonance (NMR), lowpressure $\mathrm{N}_{2}$ and/or $\mathrm{CO}_{2}$ adsorption, and ultra-small angle neutron scattering techniques (USANS) have been used to study pore size, volume and surface area of gas shale. ${ }^{[-19}$

In order to reflect the complexity and heterogeneity of pore structures in gas shale, fractal theory has been introduced. In mathematics, a fractal is used to describe and simulate naturally occurring objects, which is initially coined by Mandelbrot in 1975 10 Although it is a mathematical tool, fractal theory has been extensively applied to many disciplines, such as physics, biology and chemistry.
In physics, fractal theory can be employed for the characterization and simulation of irregular and fragmented objects with non-Euclidean shapes.11-13 As far as the petroleum and natural gas research field, the fractal investigation is usually used to analyze the pore structures of rock reservoirs (sandstone, coal and shale, etc.), where the fractal theory considers the complex pore structures as a whole.1213 The fractal analysis has an ability to quantitatively characterize the heterogeneity and irregularity of the pore surface by using the parameter of fractal dimension $D$, in which the fractal dimension $D$ is a ratio providing a statistical index of complexity comparing how detail in a fractal pattern changes with the scale at which it is measured! ${ }^{[2] 14}$ For the characterization of shale gas reservoirs, fractal analyses were carried on many different shale reservoirs, including Niutitang shale from the Sichuan basin (China) ${ }^{2}$ Barnett shale from the Worth basin (USA) $\sqrt{15}$ and Bakken shale from the Williston basin (USA), ${ }^{16}$ etc. Existing research found that fractal characteristics have a significant influence on gas adsorption/flow capacities, especially on the permeable pathways for methane transport during shale gas extraction, indicating that fractal properties probably influence the shale gas production and thus can be used as a parameter to evaluate the quality of a shale reservoir.17-19 
Therefore, improving the fractal characterization of pore structures in shale is of great importance for shale gas exploration and exploitation.

So far, it is a common phenomenon all over the world that the commercial gas extraction from marine and that from continental shale are pretty unbalanced. In the US, more than $70 \%$ of current shale gas production was extracted from marine shales in the Devonian-Mississippian period, mainly including Antrim shale, Ohio shale, New Albany shale, Marcellus shale, Barnett shale, Fayetteville shale and Woodford shale. $20-22$ In China, the commercial breakthrough for shale gas extraction has hitherto been made only in marine shale but not yet in continental shale, even though there contains huge shale gas potential in continental shale .23 Marine and continental shales were formed under disparate sedimentary conditions and therefore have some different properties. To describe the distinction between marine and continental shales, their water imbibition, geochemistry, mineralogy, petrology and hydrocarbon accumulation conditions were contrastively investigated..$^{24} \sqrt[26]{ }$ However, little attention from previous researches has been paid to the comparison of pore fractal characterization between marine and continental shales.

In this study, a comparison of marine shale and continental shale was made from the fractal view, which aims at exploring the potential differences in fractal characterization between marine and continental shales. For this purpose, low-pressure $\mathrm{N}_{2}$ adsorption analysis was employed because it has been proven as an effective method to investigate pore structures and fractal characteristics of shale reservoirs 182730 In addition, for both the marine and continental shales, the relationships between fractal dimensions and conventional reservoir parameters (mineral constituents, content of total organic carbon (TOC), porosity, permeability and methane adsorption capability) were also discussed. These investigations are helpful for understanding the controlling factors of pore development, as well as the gas accumulation mechanisms in marine and continental shales.

\section{MATERIALS AND ANALYTICAL METHODS}

\subsection{Samples}

In this study, nine marine shale core samples were obtained from the Lower Silurian Longmaxi (LSL) formation in the Jiaoshiba shale gas field of southeastern Sichuan basin, southwest China. The LSL formation originated from typical marine sediments and is the most successful stratum for commercial shale gas production in China so far ${ }^{3132}$ Moreover, nine continental shale samples were collected from a freshly exposed outcrop of the Middle Jurassic Dameigou (MJD) formation at Yueyashan profile of southern Altun Mountains, in western Qaidam basin of northwest China. The MJD formation in the sampling location, deposited in a lacustrine environment, is a pretty promising stratum for shale gas exploration because of its huge gas resources potential. 33 Lithologically, all collected samples were black, organic-rich carbonaceous shales.

\subsection{Experimental Methods}

Mineral constituent, TOC content, porosity, permeability and methane adsorption capacity were investigated to characterize the reservoir properties. Among them, the measurements of porosity and permeability were made on the core plugs (diameter of 1 inch), while others were made with small blocks or powders crushed from the remaining core cuttings. The porosities were analyzed using the helium pycnometry, and the helium gas permeabilities were measured at overburden pressure. The mineral constituent was analyzed by X-ray diffraction (XRD) method using shale powders (grain size of 100 mesh) at $40 \mathrm{kV}$ and $40 \mathrm{~mA}$ with a $\mathrm{Cu}-\mathrm{K} \alpha$ radiation. For TOC content measurements, the core cuttings were crushed to pass through a $0.5 \mathrm{~mm}$ sieve. The TOC content was measured by a carbon sulfur analyzer after the prepared powders were treated with hydrochloric acid to remove the carbonates. The methane adsorption capacities were determined by equilibrium methane adsorption isotherms, which were performed at $30^{\circ} \mathrm{C}$ and up to $11 \mathrm{MPa}$ based on the Langmuir theory.

For the pore structure and fractal characterization, low pressure $\mathrm{N}_{2}$ adsorption experiment was conducted on all collected shale samples. The $\mathrm{N}_{2}$ adsorption isotherms were obtained at $77 \mathrm{~K}$ with the relative pressure $\left(P / P_{0}\right)$ ranging from 0.01 to 0.995 . The specific surface area was analyzed with the Brunauer-Emmette-Teller (BET) method, while the total pore volume and average pore diameter were obtained by the Barrette--Joynere-Halenda (BJH) model. Besides, the Field-Emission Scanning Electron Microscope (FE-SEM) was used to image the pore characteristics of collected shales. 


\subsection{Fractal Dimension Theory}

Fractal dimension of porous material can be measured with various methods on the basis of gas adsorption isotherms, such as FrenkelHalsey-Hill (FHH) method, Brunauer-EmmettTeller (BET) method and Dubinin-Radushkevich (DR) method 29|35|36 Among which, the FHH method has been widely and successfully used for calculating fractal dimension of porous materials using $\mathrm{N}_{2}$ adsorption data, 18/28/37/38 which is also employed in this study. The FHH model can be expressed as follows:

$$
\ln V=A\left\{\ln \left[\ln \left(\frac{P_{o}}{P}\right)\right]\right\}+C
$$

where $V$ is the volume of adsorbed gas at the equilibrium pressure $P ; P_{o}$ is the saturation pressure of the gas; $C$ is the constant of gas adsorption; and, $A$ represents the power-law exponent that is dependent on the fractal dimension $D$ and the mechanism of adsorption, and can be calculated from the slope of the plot of $\ln V$ versus $\ln \left(\ln \left(P_{o} / P\right)\right)$.

In the FHH model, the parameter $A$ in Eq. (1) equals $(D-3) / 3$ if the van der Waals attractive forces are dominant between adsorbent and adsorbate $\frac{37}{37}$ or $A$ is equal to $D-3$ while the adsorbent-adsorbate interface is controlled by the gas/liquid surface tension. ${ }^{35139}$ Zhang et al. ${ }^{40}$ stated that $A=(D-3) / 3$ holds true only if the capillary action can be ignored, and $A=D-3$ should be adopted in the FHH model because the $\mathrm{N}_{2}$ adsorption is primarily dominated by the capillary condensation regime. Furthermore, referring to previous achievements, the former calculation method (i.e. $A=(D-3) / 3)$ usually deviates from the definition for fractal dimension of pore surface and pore structure, while the latter one (i.e. $A=D-3)$ can effectively perform the realistic fractal dimension. $\frac{18 / 29 / 38}{}$ Thus, in this study, the expression " $A=D-3$ " is adopted for the $\mathrm{FHH}$ model.

By FHH model, the fractal dimension $D$ in this study yields the following equation:

$$
\ln V=(D-3)\left\{\ln \left[\ln \left(\frac{P_{o}}{P}\right)\right]\right\}+C .
$$

In general, the fractal dimension $D$ ranges from $D=2$, for perfectly smooth surfaces, to $D=3$, for sponge-like surfaces whereas the degree of surface

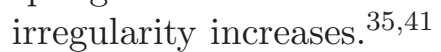

\section{RESULTS}

\subsection{Basic Characteristics of Shale Reservoir}

The mineral constitutes are dominated by quartz and clay minerals for both marine and continental shales, but there exists difference in the specific content (Fig. 1). Basically, the marine shale has higher quartz content but a lower content of clay minerals than the continental shale (Fig. 1). The quartz content in marine shale averages $52.7 \%$ with a range of $42.8 \%-64.7 \%$, while it is $37.9 \%$ on average and ranges between $30.1 \%$ and $47.3 \%$ for continental shale. As far as the content of clay minerals, it averages $25.9 \%$ and varies from $10.2 \%$ to

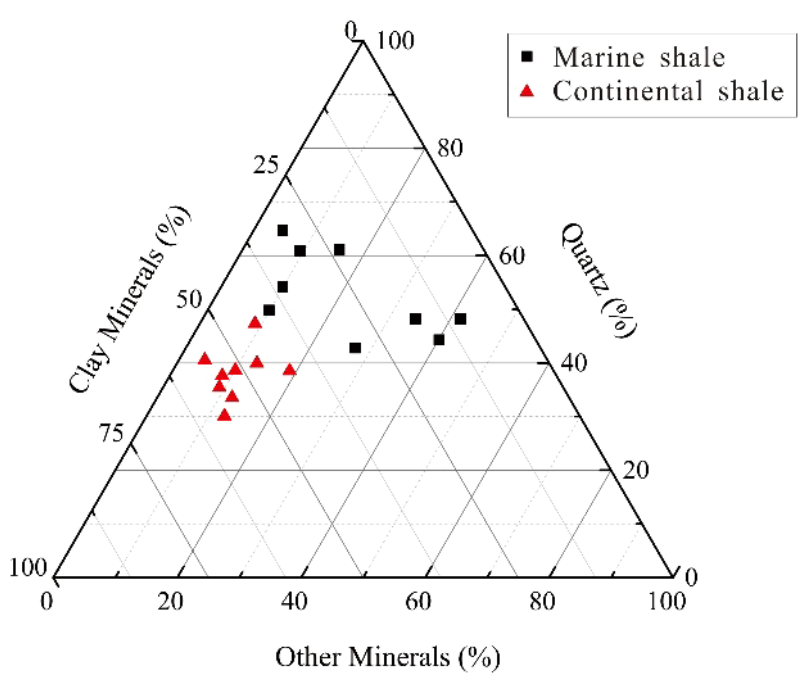

Fig. 1 Triangular diagram of minerals mass fraction for marine and continental shales.

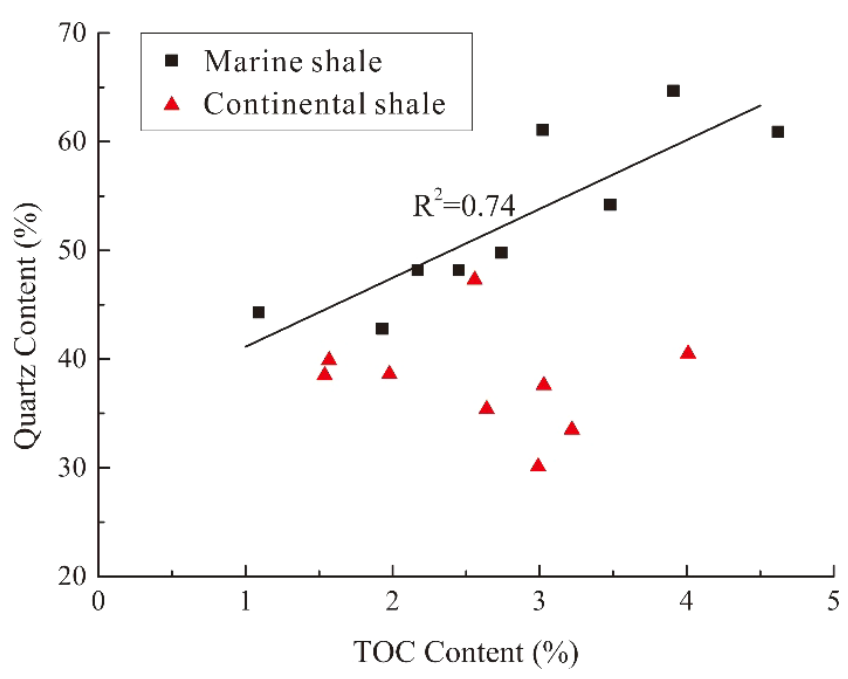

Fig. 2 The relationship between TOC content and quartz content of marine and continental shales. 


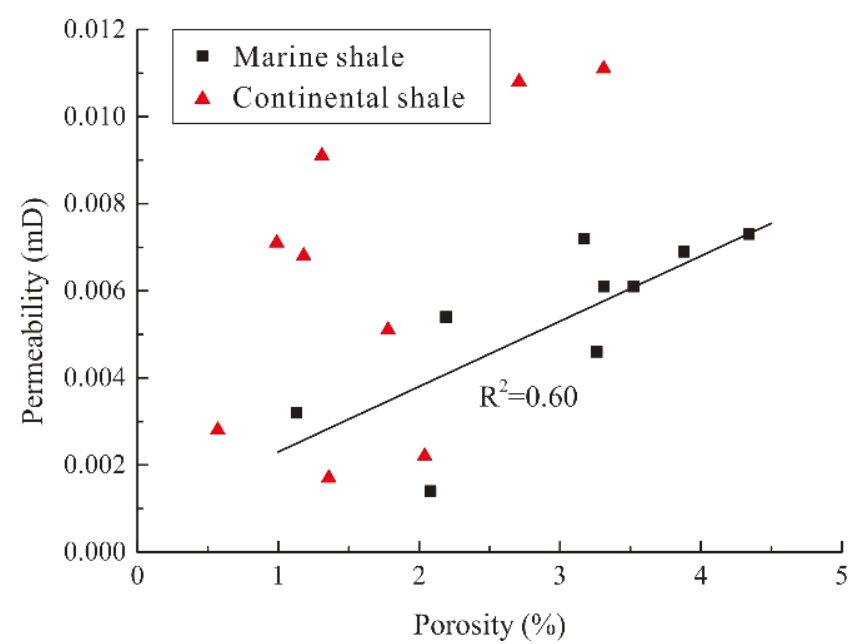

Fig. 3 The relationship between porosity and permeability of marine and continental shales.

$40.3 \%$ for marine shale, but that is $51.3 \%$ on average within a scope of $42.6 \%-57.3 \%$ for continental shale.

The marine shale also holds a slightly higher TOC content than the continental shale, as it averages $2.82 \%$ and $2.62 \%$ for marine and continental shales, respectively (Fig. 21). Furthermore, it is reported that a positive linear correction between TOC content and quartz content in shale usually means that some of the TOC were contributed from biogenic quartz, $\underline{42,43}$ otherwise, the quartz mainly derived from terrigenous debris.444 In this study, a positive relationship between TOC content and quartz content only exists in marine shale but not in continental shale (Fig. 2), indicating that abundant biogenic quartz most likely present in marine shale and the major quartz in continental shale is due to terrigenous debris.

The marine shale contains a higher porosity but a lower permeability when compared to the continental shale (Fig. 3). There is a positive correlation between porosity and permeability in marine shale rather than in continental shale (Fig. 3), suggesting that the pore connectivity is good in marine shale but not in continental shale. This is probably because the marine shale experienced stronger diagenesis and more tectonism than the continental shale as the Silurian marine shale was formed much earlier than the Jurassic continental shale, resulting in the marine shale has more micro-fractures connecting isolated pores when compared with the continental shale. This speculation can be verified by the SEM pictures (Figs. 4a 4 r). However, more reasons for this phenomenon need further studies.

The methane adsorption results demonstrate that the marine shale has lower methane adsorption capacity than the continental shale. The Langmuir volume $\left(V_{L}\right)$ of marine shale averages $2.29 \mathrm{~m}^{3} / \mathrm{t}$ while it is $3.25 \mathrm{~m}^{3} / \mathrm{t}$ on average for continental shale (Fig. 51). For both two studied shales, there is a positive correlation between TOC content and Langmuir volume (Fig. 5), indicating shale with higher TOC content usually has higher methane adsorption capacity no matter which depositional environment the shale originated from. However, the slope of TOC content versus. $V_{L}$ for marine shale
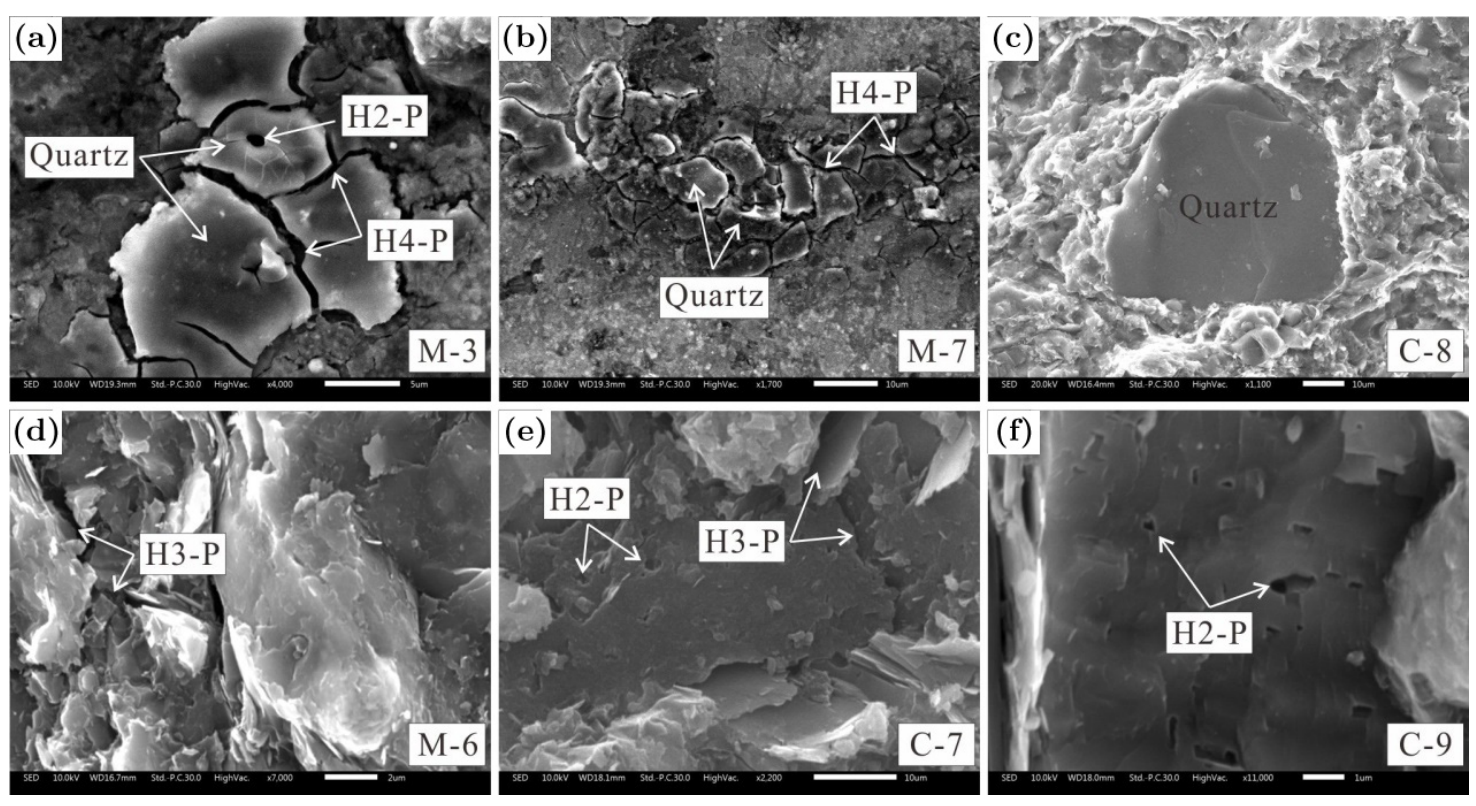

Fig. 4 SEM pictures of collected shale samples. H2-P, inkbottle-shaped pore; H3-P, plate-like pore; H4-P, slit-shaped pore. 


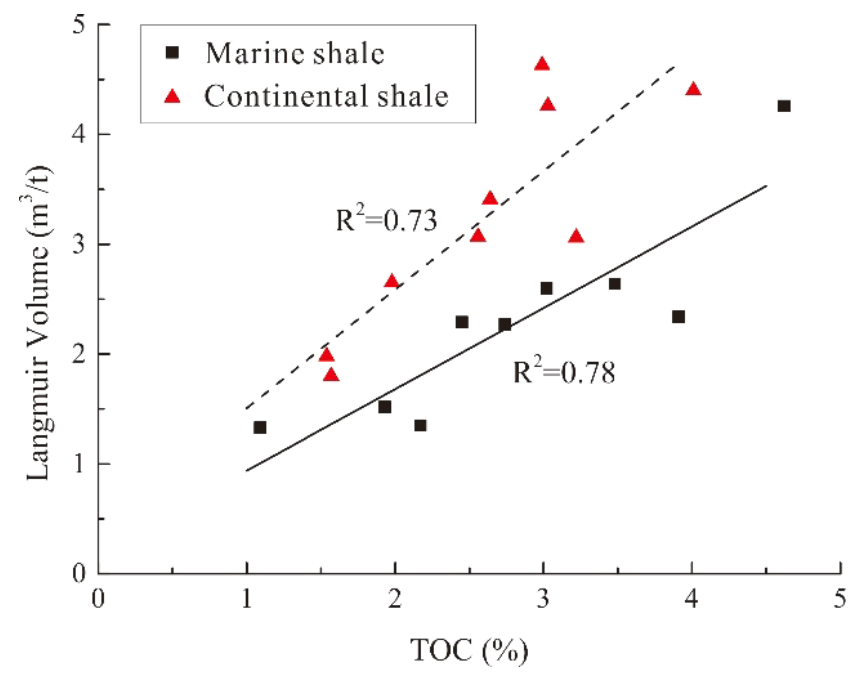

Fig. 5 The relationship between TOC content and Langmuir volume of marine and continental shales.

is slightly smaller than that for continental shale (Fig. 5), suggesting the methane adsorption capacity of marine shale is less sensitive to the variation of TOC content when compared to the situation of continental shale. This results in that the marine shale has a similar TOC content but a lower methane adsorption capacity than the continental shale.

\section{2. $\mathrm{N}_{2}$ Gas Adsorption-Desorption Isotherms and Pore Structure}

The $\mathrm{N}_{2}$ gas adsorption-desorption isotherms of marine shale and continental shale are illustrated in Figs. 6 and 7, respectively. The $\mathrm{N}_{2}$ adsorption isotherms of all collected samples are of Type IV, with noticeable hysteresis loops (Figs. [6 and 7), according to the International Union of Pure and Applied Chemistry (IUPAC) classification. The presence of hysteresis suggests that evaporation from pores is a distinctly different process than condensation within the pores, and indicates the occurrence of capillary condensation within the mesopores 45/46 A "sudden drop" of desorption branch occurred at around $P / P_{0}$ of 0.5 and this phenomenon is referred to as the Tensile Strength Effect 47 The disappearance of the hysteresis at lower $P / P_{0}$ is the result of instability of the hemispherical meniscus during desorption in pores with critical diameters $(\sim 4 \mathrm{~nm}) ! 47$

The shape of hysteresis loop, obtained from $\mathrm{N}_{2}$ gas adsorption-desorption isotherms, reflects the pore type. ${ }^{46}$ The pore types of both marine and continental shales are composed of $\mathrm{H} 2$ (inkbottleshaped pore), H3 (plate-like pore) and H4 (slitshaped pore) (Figs. 6 and 7). The H2 type reflects
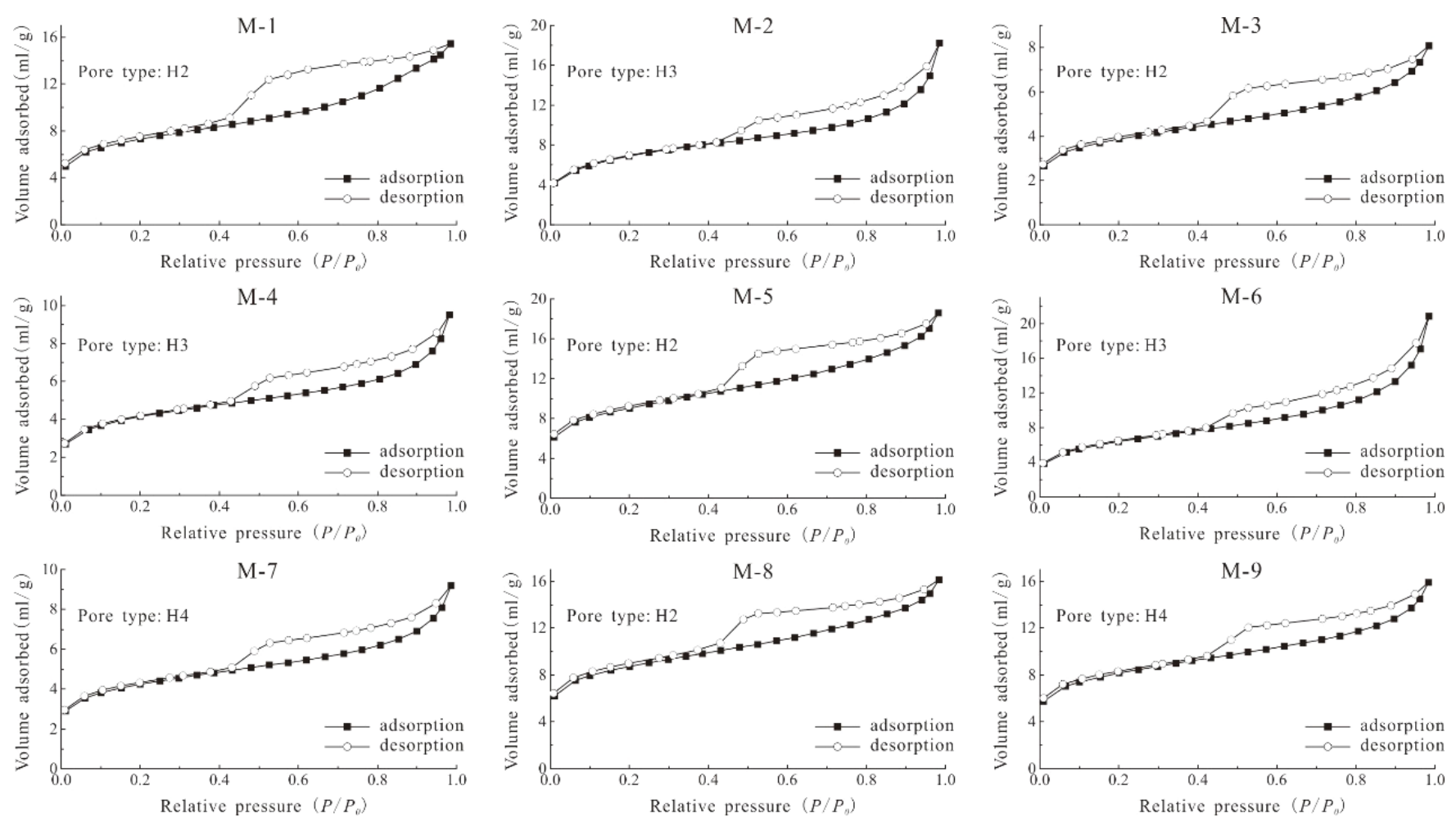

Fig. 6 Nitrogen adsorption-desorption isotherms of marine shale. 

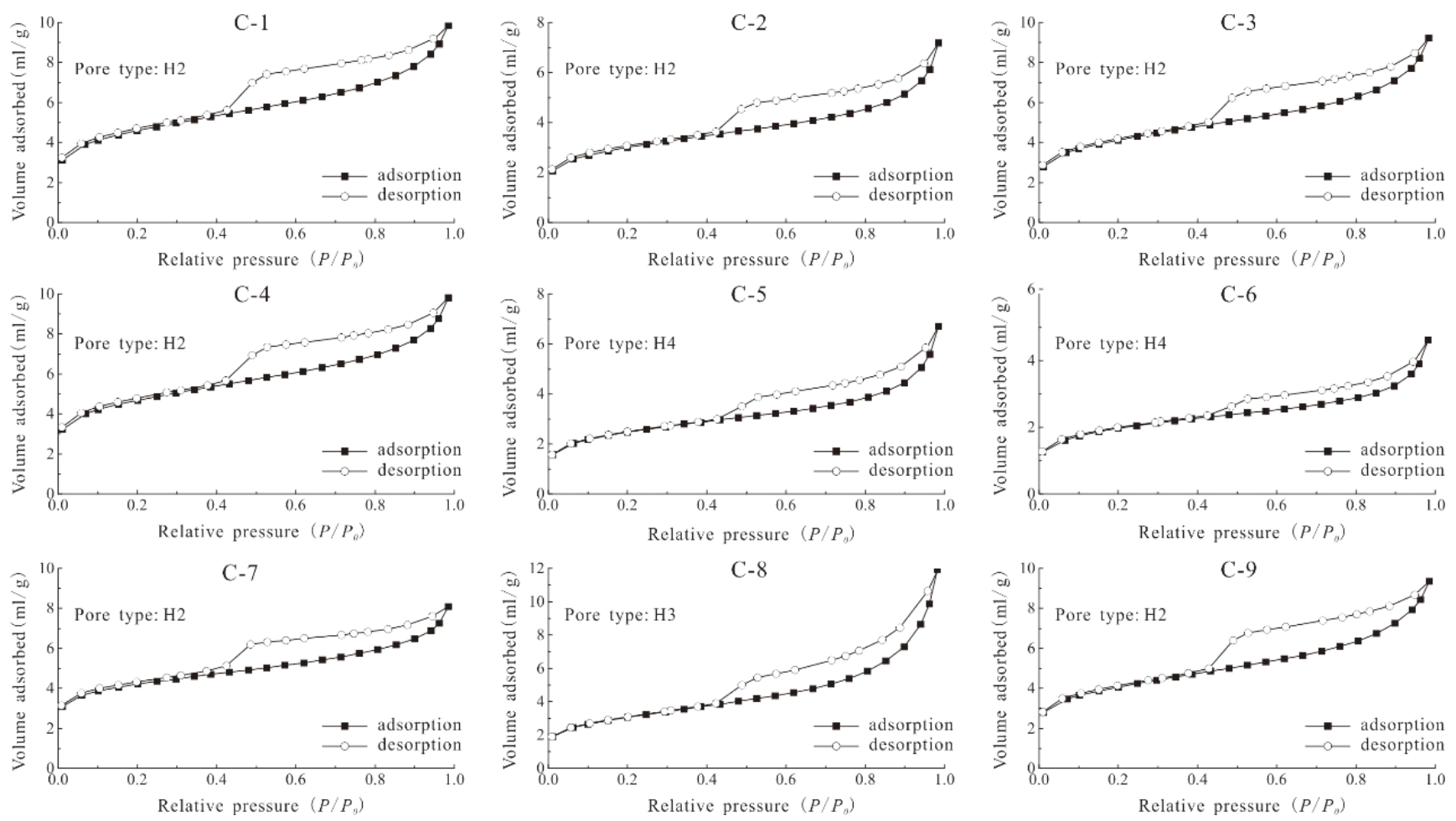

Fig. 7 Nitrogen adsorption-desorption isotherms of continental shale.

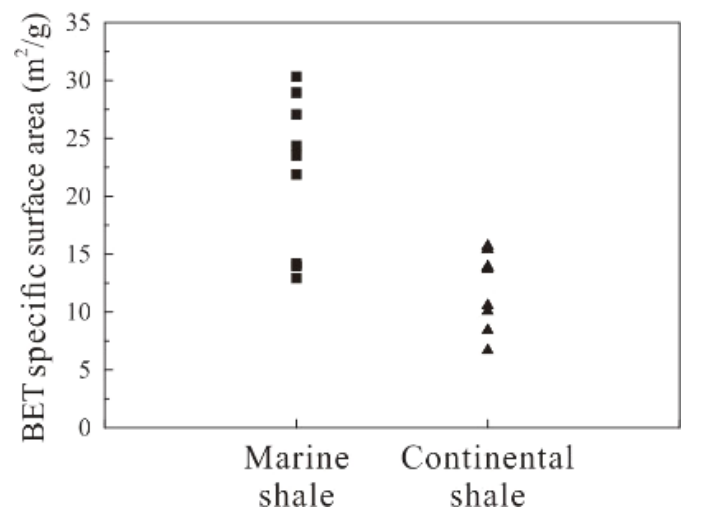

(a)

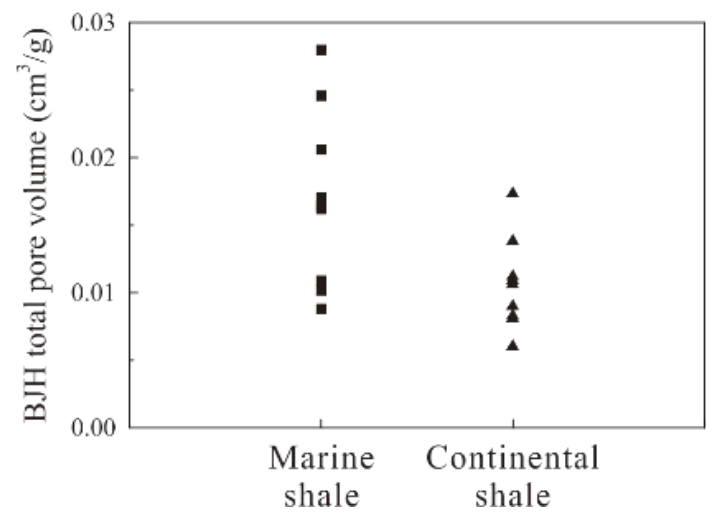

(b)

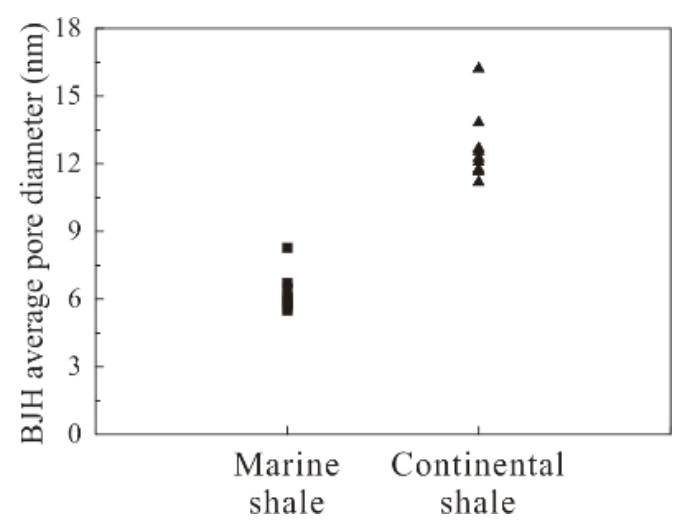

(c)

Fig. 8 Pore structure parameters of marine and continental shales. 


\section{J. Liu et al.}

the pores with narrow necks and wide bodies and thus it is good for shale gas accumulation but bad for gas seepage, while the H3 and H4 types are advantageous to the flow of hydrocarbons for their excellent openness. In reality, the pores in marine shale has fewer $\mathrm{H} 2$ type but more $\mathrm{H} 3+\mathrm{H} 4$ types than those in continental shale (Figs. 6 and 7), which is consistent with the SEM observation (Fig. 4). Thus higher proportion of pores in marine shale is associated with gas seepage when compared to the situation in continental shale, which is just in accordance with the positive relationship between porosity and permeability existing in marine shale rather than in continental shale. In general, this may cause that the gas extraction from marine shale is easier than that from continental shale.

In terms of pore structure parameters, the marine shale generally has higher value of specific surface area and total pore volume but smaller value of average pore diameter than the continental shale
(Fig. 8). The mean value of specific surface area (Fig. 8a), total pore volume (Fig. 8b) and average pore diameter (Fig. 8k) for marine shale samples respectively is $21.9 \mathrm{~m}^{2} / \mathrm{g}, 0.017 \mathrm{~cm}^{3} / \mathrm{g}$ and $6.28 \mathrm{~nm}$, while that for continental shale samples respectively is $12.03 \mathrm{~m}^{2} / \mathrm{g}, 0.011 \mathrm{~cm}^{3} / \mathrm{g}$ and $12.69 \mathrm{~nm}$. As suggested by the studies of $\mathrm{CaO}$ et al $\frac{48}{2}$ and $\mathrm{Hu}$ et al.,$\frac{49}{}$ the distinction in pore structure parameters between two studied shales indicates that marine shale contains more micropores and mesopores than continental shale.

\subsection{Fractal Dimensions from $\mathrm{N}_{2}$ Adsorption Isotherms}

According to Eq. (2), obtained from the original low-pressure $\mathrm{N}_{2}$ adsorption data, the plots of $\ln V$ versus $\ln \left(\ln \left(P_{o} / P\right)\right)$ for marine shale and continental shale are shown in Fig. 9 and Fig. 10, respectively. Diagrams exhibit that two distinct
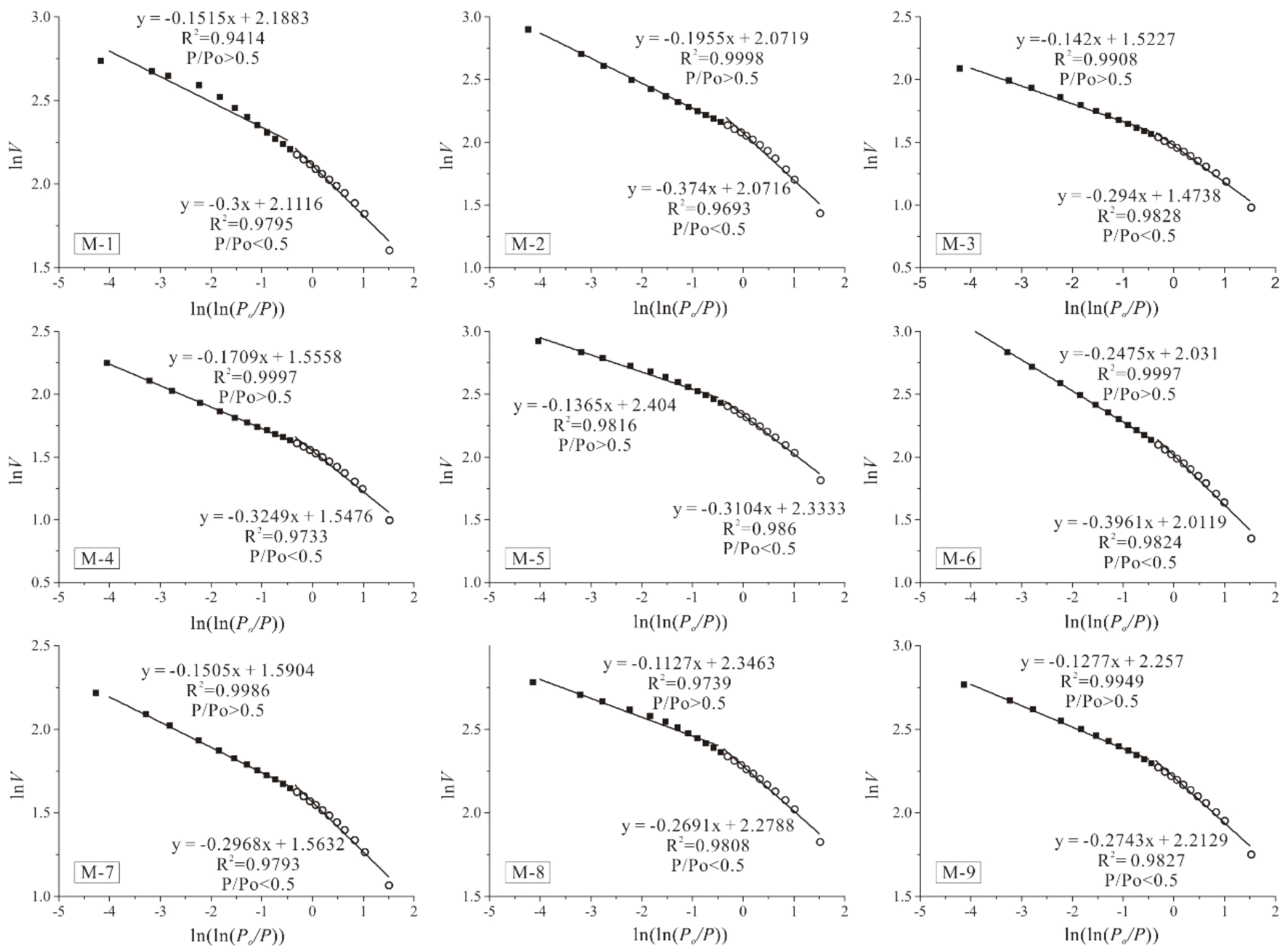

Fig. 9 Plots of $\ln V$ versus $\ln (\ln (P o / P))$ of $\mathrm{N}_{2}$ adsorption data of marine shale. 

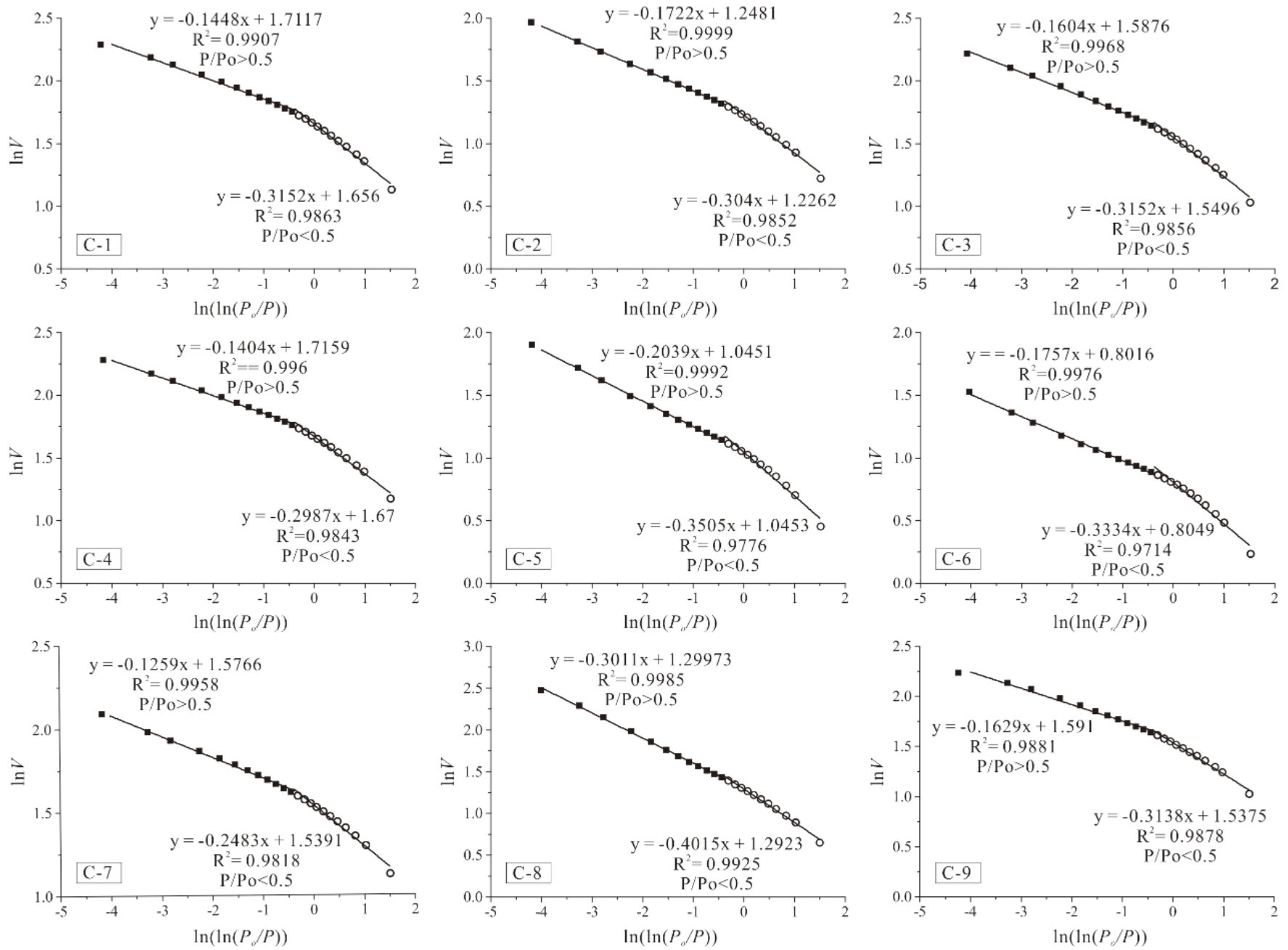

Fig. 10 Plots of $\ln V$ versus $\ln \left(\ln \left(P_{o} / P\right)\right)$ of $\mathrm{N}_{2}$ adsorption data of continental shale.

linear segments exist at $P / P_{o}$ intervals of $0-0.5$ and $0.5-1$, probably suggesting different mechanisms for gas adsorption in these two regions. $\frac{29}{2}$ In this study, we use $A_{1}$ and $D_{1}$ (or $A_{2}$ and $D_{2}$ ) to represent the slope of the plot of $\ln V$ versus $\ln \left(\ln \left(P_{o} / P\right)\right)$ and the fractal dimension at $P / P_{o}$ of $0-0.5$ (or 0.5-1), respectively (Table 1 ). According to Groen et al., 47 the $P / P_{0}$ interval of $0-0.5$ is relevant to the pores with diameters less than $\sim 4 \mathrm{~nm}$, while the $P / P_{0}$ interval of $0.5-1$ corresponds with lager pores (diameter $>\sim 4 \mathrm{~nm}$ ).

In general, both the fractal dimensions $\left(D_{1}\right.$ and $D_{2}$ ) of all studied samples are far from 2 and closer to 3 (Table 1), indicating that the pore surface and pore structure of shales are heterogeneous. For both marine and continental shales, the fractal dimension $D_{2}$ is generally greater than fractal dimension $D_{1}$ (Table 1), suggesting that larger pores (diameter $>\sim 4 \mathrm{~nm}$ ) have a more serious surface irregularity and more complex pore structure than small pores (diameter $<\sim 4 \mathrm{~nm}$ ). Besides, unlike the discrepancies in dimension $D_{1}$ and $D_{2}$ of coals, $\frac{29}{, 2}$ there is a pretty positive correlation between dimension $D_{1}$ and $D_{2}$ for both two studied shales (Fig. 11), which keeps consistent in the previous viewpoints. $\underline{5051}$ This means that both fractal dimensions $\left(D_{1}\right.$ and $D_{2}$ ) can be used to effectively evaluate the heterogeneity of pore surface and structure in shale.

The fractal dimension $D_{1}$ of marine shale varies from 2.604 to 2.731 and averages 2.685, which is roughly equal to that of continental shale with a mean value of 2.680 and a range of 2.599-2.752 (Table 1). This suggests the heterogeneity of small pores (diameter $<\sim 4 \mathrm{~nm}$ ) in marine shale is approximate to that in continental shale. The fractal dimension $D_{2}$ of marine shale (average of 2.841) is slightly higher than that of continental shale (2.824 on average) (Table 1), indicating the marine shale holds more complex geometry for lager pores (diameter $>\sim 4 \mathrm{~nm}$ ) than the continental shale. 
Table 1 Fractal Dimensions Derived From Low-Pressure $\mathrm{N}_{2}$ Adsorption Data by the FHH Model.

\begin{tabular}{|c|c|c|c|c|c|c|c|c|c|}
\hline \multirow{3}{*}{$\begin{array}{l}\text { Sample } \\
\text { ID }\end{array}$} & \multicolumn{4}{|c|}{ Marine Shale } & \multirow{3}{*}{$\begin{array}{c}\text { Sample } \\
\text { ID }\end{array}$} & \multicolumn{4}{|c|}{ Continental Shale } \\
\hline & \multicolumn{2}{|c|}{$P / P_{o}=0-0.5$} & \multicolumn{2}{|c|}{$P / P_{o}=0.5^{-1}$} & & \multicolumn{2}{|c|}{$P / P_{o}=0-0.5$} & \multicolumn{2}{|c|}{$P / P_{o}=0.5^{-1}$} \\
\hline & $A_{1}$ & $D_{1}=A_{1}+3$ & $A_{2}$ & $D_{2}=A_{2}+3$ & & $A_{1}$ & $D_{1}=A_{1}+3$ & $A_{2}$ & $D_{2}=A_{2}+3$ \\
\hline M-1 & -0.300 & 2.700 & -0.152 & 2.849 & $\mathrm{C}-1$ & -0.315 & 2.685 & -0.145 & 2.855 \\
\hline $\mathrm{M}-2$ & -0.374 & 2.626 & -0.196 & 2.805 & $\mathrm{C}-2$ & -0.304 & 2.696 & -0.172 & 2.828 \\
\hline M-3 & -0.294 & 2.706 & -0.142 & 2.858 & $\mathrm{C}-3$ & -0.315 & 2.685 & -0.160 & 2.840 \\
\hline M-4 & -0.325 & 2.675 & -0.171 & 2.829 & C-4 & -0.299 & 2.701 & -0.140 & 2.860 \\
\hline M-5 & -0.310 & 2.690 & -0.137 & 2.864 & $\mathrm{C}-5$ & -0.351 & 2.650 & -0.204 & 2.796 \\
\hline M-6 & -0.396 & 2.604 & -0.248 & 2.753 & C-6 & -0.333 & 2.667 & -0.176 & 2.824 \\
\hline M-7 & -0.297 & 2.703 & -0.151 & 2.850 & $\mathrm{C}-7$ & -0.248 & 2.752 & -0.126 & 2.874 \\
\hline M-8 & -0.269 & 2.731 & -0.113 & 2.887 & C-8 & -0.402 & 2.599 & -0.301 & 2.699 \\
\hline M-9 & -0.274 & 2.726 & -0.128 & 2.872 & C-9 & -0.314 & 2.686 & -0.163 & 2.837 \\
\hline
\end{tabular}

Note: The values of $A_{1}$ and $A_{2}$ for marine shale were exhibited in Fig. 9 and for continental shale in Fig. 10]

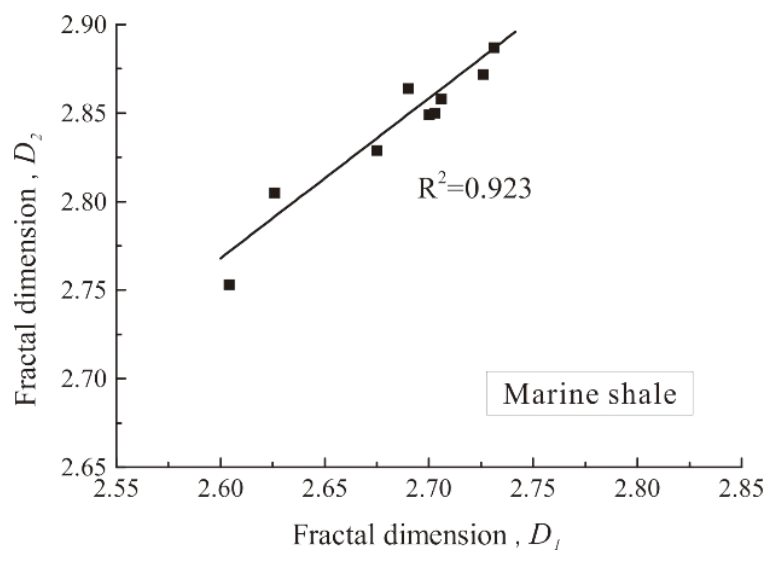

(a)

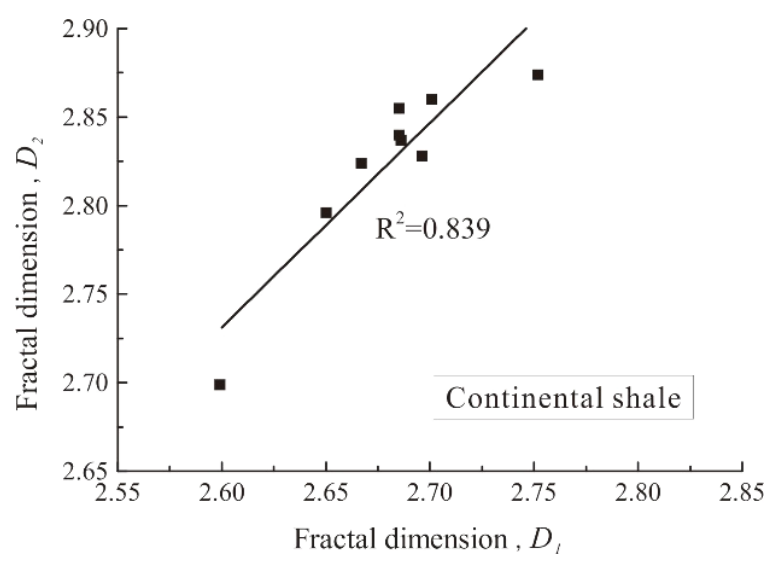

(b)

Fig. 11 Fractal dimensions $D_{1}$ versus $D_{2}$ of (a) marine shale and (b) continental shale.

\section{DISCUSSION}

\subsection{Relationships between Fractal Dimensions and Mineral Constituents and TOC Content}

The fractal dimensions $\left(D_{1}\right.$ and $\left.D_{2}\right)$ show a slightly positive correlation with the quartz content in marine shale (Fig. 12a) but not in continental shale (Fig. 12b), resulting from the pore system related to quartz in marine shale is more developed than that in continental shale. This phenomenon can be partially explained like this, the stronger diagenesis and more tectonism experienced by the marine shale made more micropores occurred in quartz as it is brittle, when compared to the situation in the continental shale. SEM pictures exhibit that the marine shale contains more pores in quartz than the continental shale (Fig. (4). For both marine and continental shales, the fractal dimensions $\left(D_{1}\right.$ and $\left.D_{2}\right)$ have a slightly positive relationship with the content of clay minerals (Figs. 12 r and $12 \mathrm{~d}$ ). The layer structure and flocculent structure of clay minerals enhance the complexity of pore surface $\frac{\sqrt{18}}{\sqrt{1}}$ thus the higher the clay content usually suggests the greater the fractal dimension. Among which, for studied two shales, the correlation coefficients of clay minerals content versus fractal dimension $D_{1}$ are greater than those of clay minerals content versus fractal dimension $D_{2}$ (Figs. $12 \mathrm{r}$ and $12 \mathrm{~d}$ ), suggesting that the clay minerals is better associated with the irregularity of small pores (diameter $<\sim 4 \mathrm{~nm}$ ).

For both two studied shales, there exist positive correlations between fractal dimensions $\left(D_{1}\right.$ and $D_{2}$ ) and TOC content (Fig. 13). This phenomenon owes to the fact that shales containing higher TOC content tend to hold more micropores and mesopores resulted from kerogen deformation during the thermal maturation process. .52153 

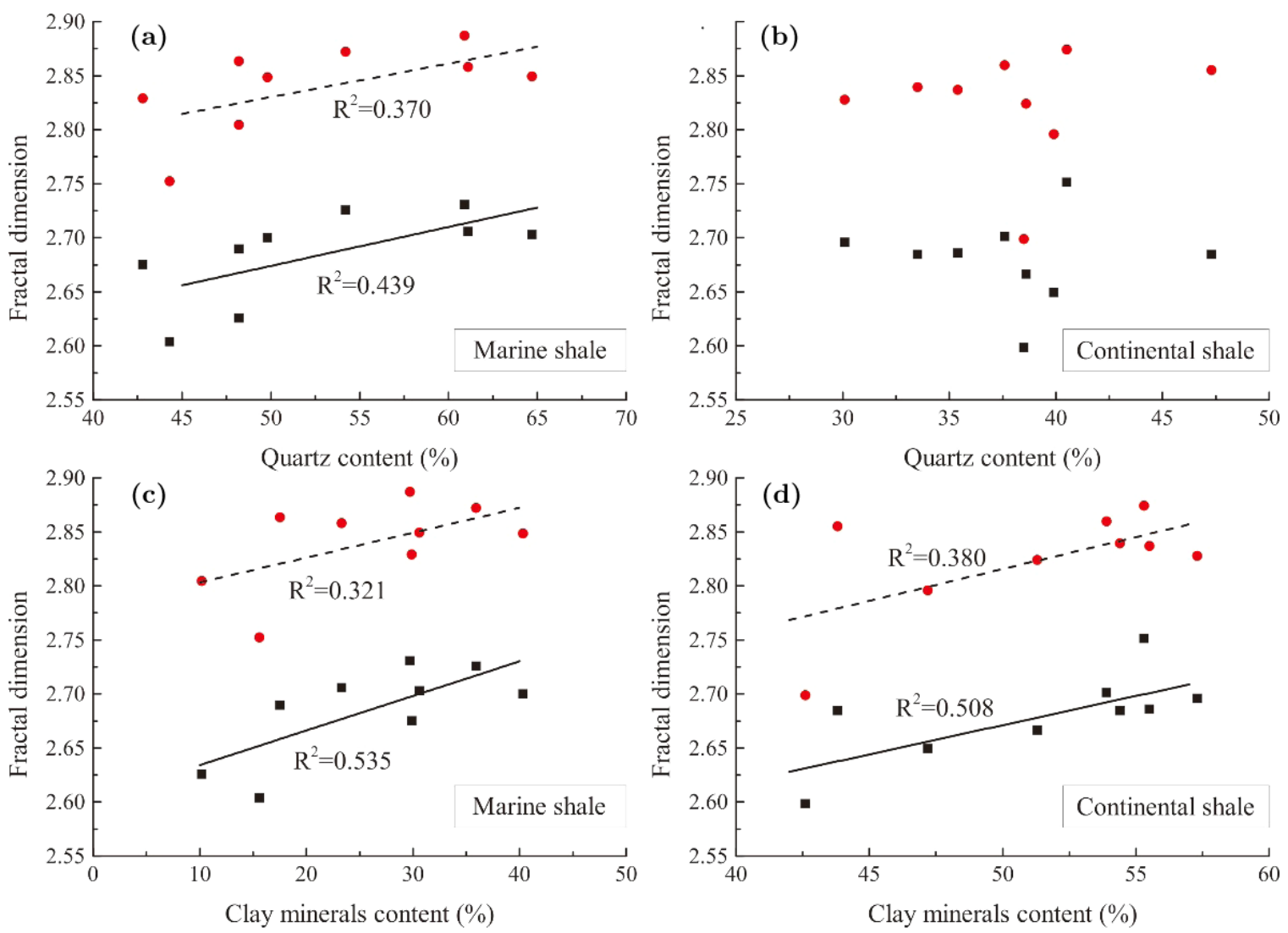

- Fractal dimension, $D_{l}$

- Fractal dimension, $D_{2}$

Fig. 12 Relationships between fractal dimensions and mineral constituents (quartz and clay minerals) for marine and continental shales.

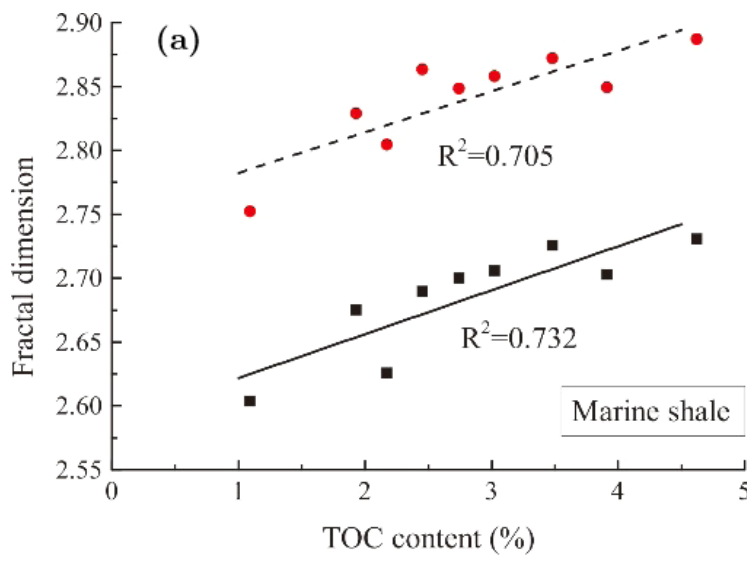

- Fractal dimension, $D_{i}$

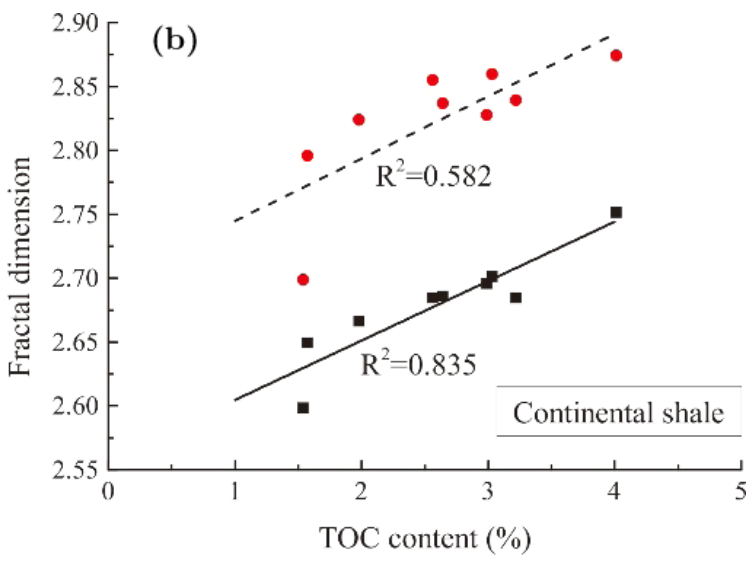

- Fractal dimension, $D_{2}$

Fig. 13 Relationships between fractal dimensions and TOC content for marine and continental shales.

These pores can build complex and heterogeneous pore networks, $\frac{18 \mid 51}{1}$ resulting in that higher TOC content is generally corresponding to larger fractal dimensions. The TOC content seems to similarly affect the pore structures of small pores (diameter $<\sim 4 \mathrm{~nm})$ and larger pores (diameter $>\sim 4 \mathrm{~nm})$ in marine shale as their approximate correlation coefficients (Fig. 13a). Comparatively, for continental shale, the heterogeneity of small pores correlates better to TOC content than that of larger pores, illustrated by the distinction of correlation coefficients (Fig. 13b). 


\subsection{Relationships between Fractal Dimensions and Porosity and Permeability}

Both marine and continental shales show a negative correlation between porosity (permeability) and fractal dimensions $\left(D_{1}\right.$ and $\left.D_{2}\right)$ (Fig. [14), which is consistent with the perspective achieved by Yang et al. ${ }^{2}$ The fractal dimensions are usually associated with the complex micropores, whereas the porosity is improved by the occurrence of mesopores and macropores. 2154 Therefore, higher porosity usually means smaller proportion of micropores amount total pores, resulted in the shale containing a higher porosity tends to have a lower pore fractal dimension (Figs. 14t and 14k).

The permeabilities for both marine and continental shales also decrease in line with the increase of fractal dimensions (Figs. 14b; Fig. 14d). Interconnections between micropores, mesopores and macropores, as well as micro-fractures in shale, play a significant role in controlling the matrix permeability of shale. The increasing number of micropores and mesopores suggests the connecting channels between pores and/or fractures are increasingly narrow, ${ }^{255}$ resulting in lower permeability. Thus, shales with greater fractal dimensions $\left(D_{1}\right.$ and $\left.D_{2}\right)$ are commonly less permeable for gas in shale, which is related to that shales with higher fractal dimensions usually contain more micropores and mesopores than those with lower fractal dimensions. It seems that the permeability of marine shale is affected by the structures of small pores (diameter $<\sim 4 \mathrm{~nm}$ ) and larger pores (diameter $>\sim 4 \mathrm{~nm})$ at a similar degree, as the approximate correlation coefficients (Fig. 14b). However, the correlation coefficients in Fig. 14d demonstrate that the permeability of continental shale is more sensitive to the structure of small pores instead of larger pores.

\subsection{Relationships between Fractal Dimensions and Pore Structure Parameters}

For both marine and continental shales, there are similar relationships between fractal dimensions
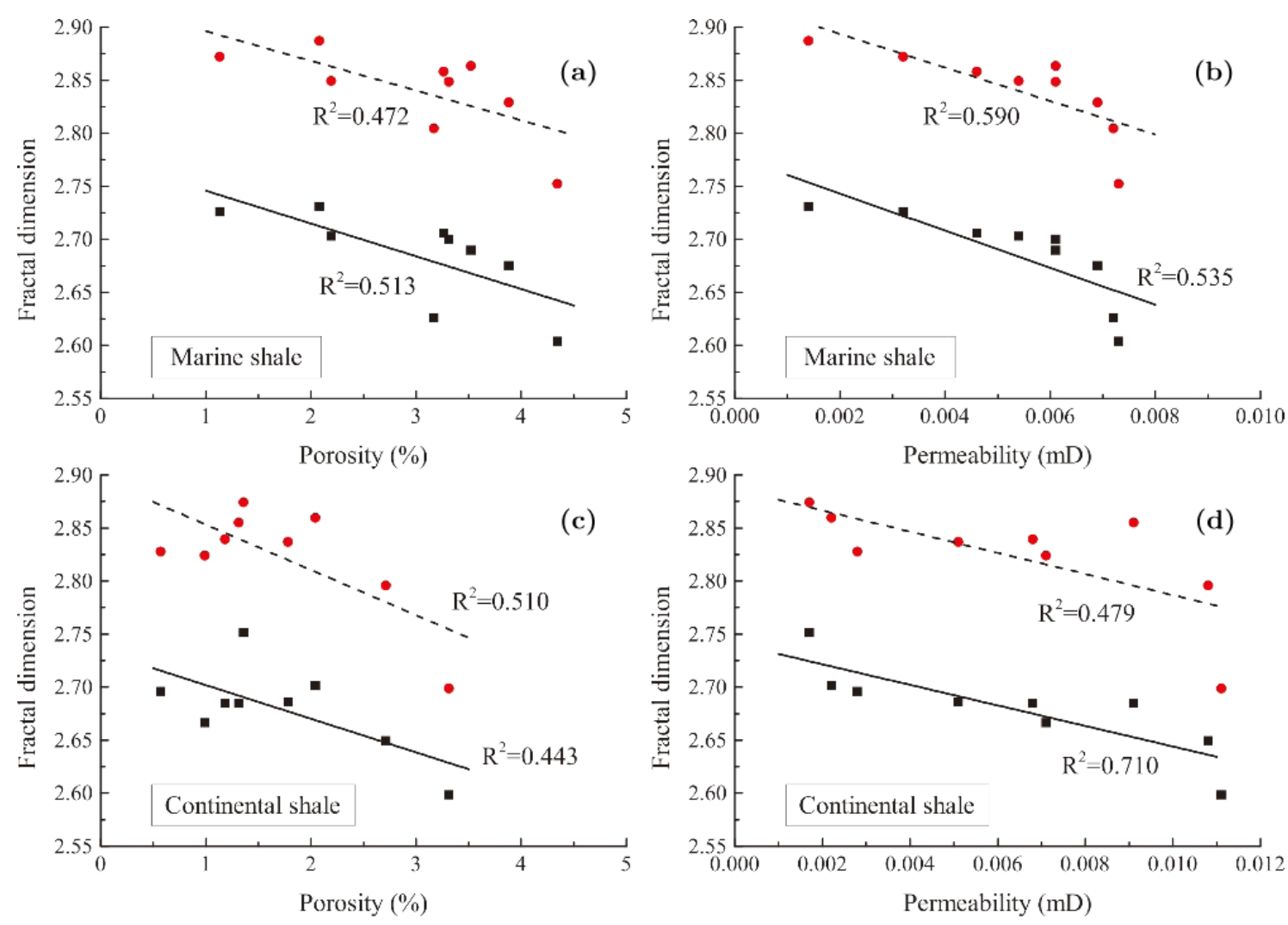

- Fractal dimension, $D_{l}$

- Fractal dimension, $D_{2}$

Fig. 14 Relationships between fractal dimensions and (a), (c) porosity, (b), (d) permeability for marine and continental shales. 

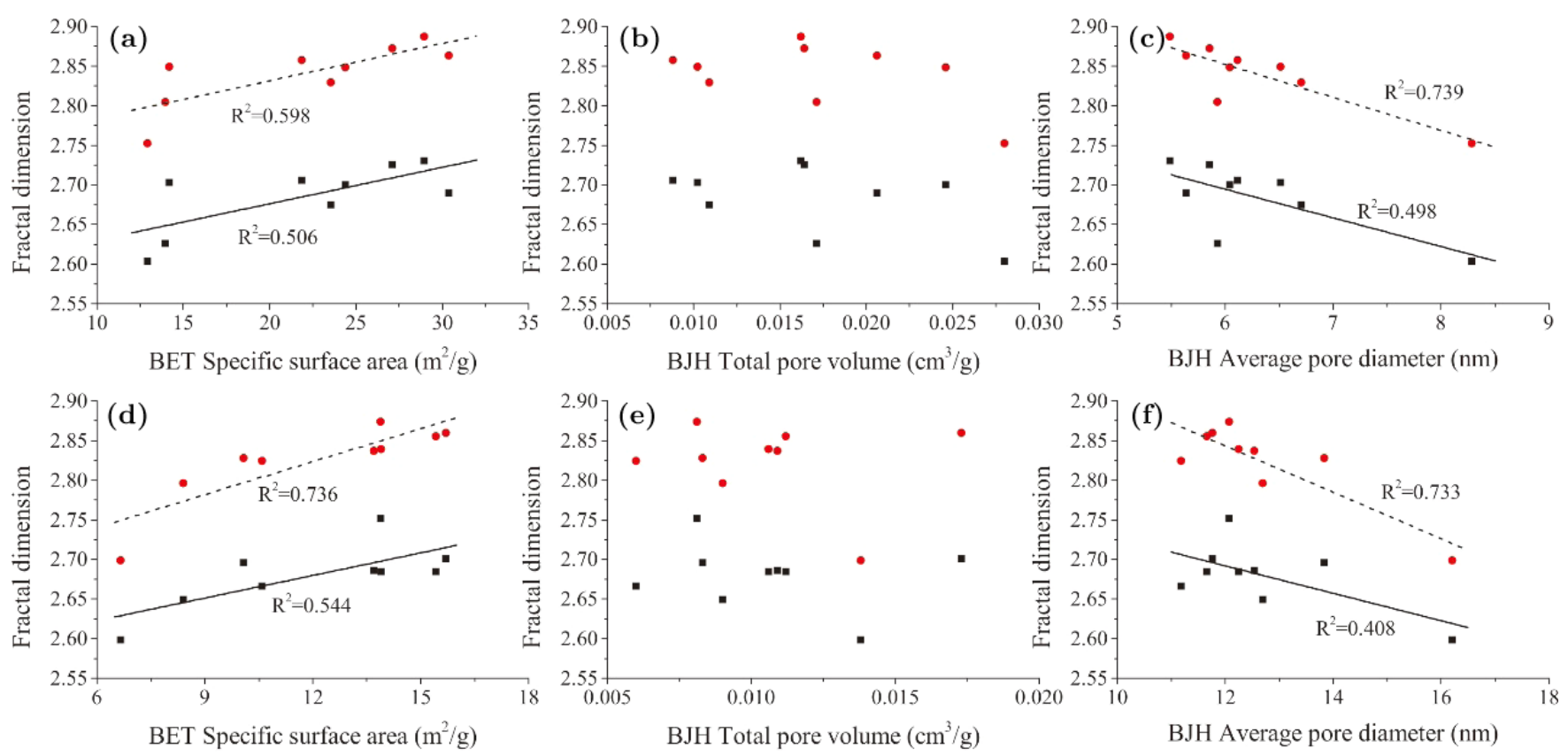
a $\quad$ b $\quad$ c c Marine shale
d e $\_$Continental shale
- Fractal dimension, $D_{i}$
- Fractal dimension, $D_{2}$

Fig. 15 Relationships between fractal dimensions and BET specific surface area, BJH total pore volume, BJH average pore diameter.

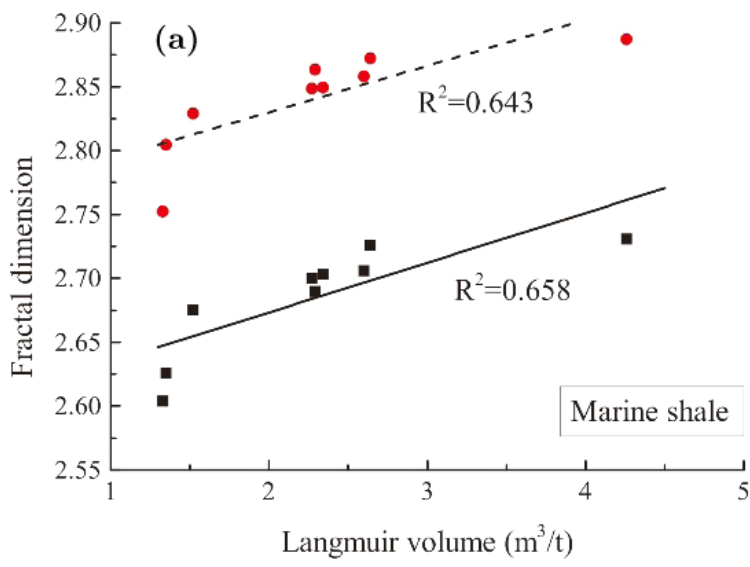

- Fractal dimension, $D_{l}$

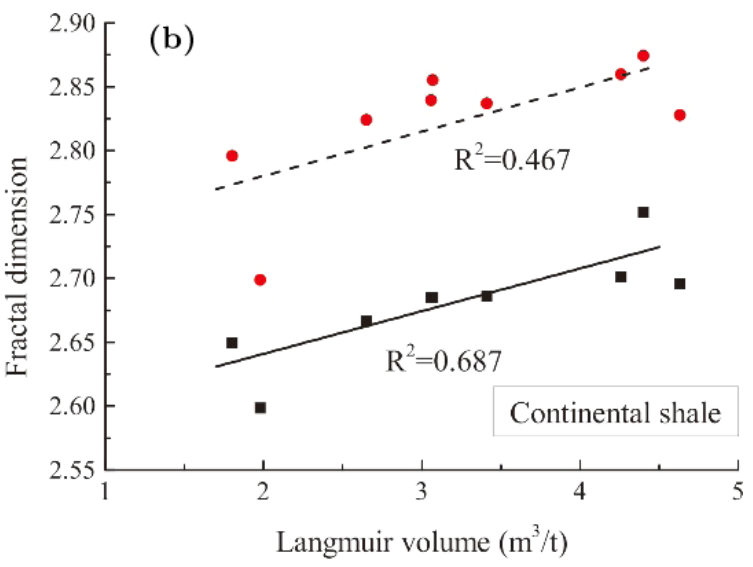

- Fractal dimension, $D_{2}$

Fig. 16 Relationship between fractal dimensions and Langmuir volume of (a) marine shale and (b) continental shale.

$\left(D_{1}\right.$ and $\left.D_{2}\right)$ and pore structure parameters (Fig. 15). The fractal dimensions have positive linear correlations with specific surface area (Figs. 15a and $15 \mathrm{~d}$ ) and weak linear correlation with total pore volume (Figs. 15b and 15b), while show a negative linear correlation with average pore diameter (Figs. 15t and 15f). No matter formed by marine or continental sediments, the shale containing greater specific surface area or smaller average pore diameter generally has higher fractal dimensions and therefore more irregular and complicated pore structures.
Logically, a greater specific surface area is usually originated by a greater surface roughness $\frac{48}{4}$ and thus positively correlates to fractal dimensions. Shale samples with smaller average pore diameter also contain more throats and micropores, leading to more heterogeneous and complicated pore structure and greater fractal dimensions as well. These small throats and microspores also enhance the complexity of pore structure in shale and hinder the gas flow in this pore network, which further explains why the shales with greater fractal dimensions commonly have lower permeability (Figs. 14b and 14d). 
However, the total pore volume is mainly associated with the space of pores and fractures in shale, while fractal dimensions $\left(D_{1}\right.$ and $\left.D_{2}\right)$ are parameters related to the irregularity of pore geometry and pore system complexity. Therefore, there is no necessary linear correlation between the total pore volume and fractal dimensions.

Additionally, for both two studied shales, fractal dimension $D_{2}$ has better correlations with specific surface area and average pore diameter than fractal dimension $D_{1}$ (Fig. 15). This demonstrates that the level of specific surface area and average pore diameter in shale can be better reflected by the situation of larger pores with diameter $>\sim 4 \mathrm{~nm}$.

\subsection{Relationships between Fractal Dimensions and Methane Adsorption Capacity}

Methane adsorption capacity of both marine and continental shales, represented by Langmuir volume in this study, positively correlates with fractal dimensions $\left(D_{1}\right.$ and $\left.D_{2}\right)$ (Fig. [16). The methane adsorption capacity in shales is positively affected by two major factors: specific surface area and adsorption potential energy. ${ }^{4565}$ The greater specific surface area can offer larger potential solid contact surface for gas molecules during the methane adsorption process. ${ }^{2}$ Shales containing higher fractal dimensions hold a greater specific surface area (Figs. $15 \mathrm{a}$ and $15 \mathrm{~d}$ ), and thus can provide more adsorption sites for methane. The adsorption potential energy is associated with the interaction force between gas molecules and a solid surface, and inversely correlates with the pore diameter. 45 Therefore, the smaller pore diameter makes the stronger adsorption potential energy. The greater fractal dimensions reflect the smaller average pore diameter in shale (Figs. 15c and 15) and thus commonly generate stronger adsorption potential energy in shale. In general, for both marine shale and continental shale, the fractal dimensions can act as a good budget for the evaluation of methane adsorption capacity.

In addition, for marine shale, the correlation coefficient of dimension $D_{1}$ versus $V_{L}$ is roughly equal to that of dimension $D_{2}$ versus $V_{L}$ (Fig. 16 $\mathrm{k}$ ), suggesting the structures of small pores (diameter $<\sim 4 \mathrm{~nm}$ ) and larger pores (diameter $>\sim 4 \mathrm{~nm}$ ) affect the methane adsorption capacity of shale at a similar degree. While, for continental shale, the distinction of correlation coefficients between dimension $D_{1}$ versus $V_{L}$ and dimension $D_{2}$ versus $V_{L}$ (Fig. 16b) suggests that the methane adsorption capacity is better correlative to the complex structure of small pores.

\section{CONCLUSIONS}

The marine shale has higher value of quartz content, porosity, specific surface area and total pore volume but lower level of clay minerals content, permeability, average pore diameter and methane adsorption capacity than the continental shale. The quartz in marine shale is mostly associated with biogenic origin, while that in continental shale is mainly due to terrigenous debris.

The marine shale has fewer inkbottle-shaped pores but more plate-like and slit-shaped pores than the continental shale. The dimension $D_{2}$ is generally greater than $D_{1}$, suggesting larger pores (diameter $>\sim 4 \mathrm{~nm}$ ) have a more serious surface irregularity than small pores (diameter $<\sim 4 \mathrm{~nm}$ ) in two shales. Averagely, the marine shale has approximate dimension $D_{1}$ but slightly greater dimension $D_{2}$ than the continental shale.

The fractal dimensions (both $D_{1}$ and $D_{2}$ ) show positive relationships with clay minerals content, specific surface area and methane adsorption capacity, but display negative correlations with porosity, permeability and average pore diameter. Besides, the correlation between fractal dimensions and quartz content for marine shale is positive, while which in continental shale is not obvious.

\section{ACKNOWLEDGMENTS}

We acknowledge financial support from the National Natural Science Foundation of China (Nos. 41472137; 41722403); Key research and development project of Xinjiang Uygur Autonomous Region (2017B03019-1); the Royal Society Edinburgh and National Natural Science Foundation China (NSFC 41711530129). We also gratefully acknowledge the financial support for 1-year visiting scholar fellowship from the China Scholarship Council (No. 201706400020).

\section{REFERENCES}

1. C. R. Clarkson et al., Innovative methods for flowunit and pore-structure analyses in a tight siltstone and shale gas reservoir, AAPG Bull. 96(2) (2012) $355-374$. 
2. F. Yang, Z. F. Ning and H. Q. Liu, Fractal characteristics of shales from a shale gas reservoir in the Sichuan basin, China, Fuel 115(1) (2014) 378-384.

3. J. Ma, H. Qi and P. Z. Wong, Experimental study of multilayer adsorption on fractal surfaces in porous media, Phys. Rev. E 59 (1999) 2049-2059.

4. X. J. Liu, J. Xiong and L. L. Liang, Investigation of pore structure and fractal characteristics of organicrich Yangchang formation shale in central China by nitrogen adsorption/desorption analysis, J. Nat. Gas Sci. Eng. 22 (2015) 62-72.

5. D. J. K. Ross and R. M. Bustin, Characterizing the shale gas resource potential of DevonianMississippian strata in the western Canada sedimentary basin: Application of an integrated formation evaluation, AAPG Bull. 92(1) (2008) 87-125.

6. C. R. Clarkson et al., Pore structure characterization of north American shale gas reservoirs using USANS/SANS, gas adsorption, and mercury intrusion, Fuel 103 (2013) 606-616.

7. R. G. Loucks et al., Morphology, genesis, and distribution of nanometer-scale pores in siliceous mudstones of the Mississippian Barnett shale, J. Sediment Res. 79 (2009) 848-861.

8. X. Wei et al., Micro-pores structure characteristics and development control factors of shale gas reservoir: A case of Longmaxi formation in XX area of southern Sichuan and northern Guizhou, J. Nat. Gas Geosci. 24(5) (2013) 1048-1059.

9. H. Tian et al., Pore characterization of organicrich lower Cambrian shales in Qiannan depression of Guizhou province, southwestern China, Mar. Petrol. Geol. 62 (2015) 28-43.

10. B. B. Mandelbrot, Les Objects Fractals: Forme, Hasard et Dimension (Flammarion, Paris, 1975).

11. A. J. Katz and A. H. Thompson, Fractal sandstone pores: Implications for conductivity and pore formation, Phys. Rev. Lett. 54(12) (1985) 1325-1328.

12. C. E. Krohn, Fractal measurements of sandstones, shales, and carbonates, J. Geophys. Res.: Sol. Ea. 93(B4) (1988) 3297-3305.

13. M. I. Ozhovan, I. E. Dmitriev and O. G. Batyukhnova, Fractal structure of pores in clay soil, At. Energy 74(3) (1993) 241-243.

14. K. Falconer, Fractal Geometry (Wiley, New York, 2003), p. 308.

15. S. O. Algerian and L. A. Labophyt, On the fractal behavior of the total organic carbon in shale gas reservoirs with an example from the Barnett shale (USA), Mon. Not. R. Astron. Soc. 21 (2015) 17-22.

16. K. Liu and M. Ostadhassan, Multi-scale fractal analysis of pores in shale rocks, J. Appl. Geophys. 140 (2017) 1-10.

17. J. C. Cai et al., Recent advances on fractal modeling of permeability for fibrous porous media, Fractals 23(1) (2015) 1540006.
18. A. Li et al., Investigation of pore structure and fractal characteristics of organic-rich shale reservoirs: A case study of lower Cambrian Qiongzhusi formation in Malong block of eastern Yunnan province, south China, Mar. Petrol. Geol. 70 (2016) 46-57.

19. D. Fan and A. Ettehadtavakkol, Semi-analytical modeling of shale gas flow through fractal induced fracture networks with microseismic data, Fuel 193 (2017) 444-459.

20. EIA, Review of emerging resources: U.S. Shale gas and shale oil plays (2011), https://www.eia.gov/ analysis/studies/usshalegas/pdf/usshaleplays.pdf.

21. M. Mastalerz et al., Porosity of Devonian and Mississippian New Albany shale across a maturation gradient: Insights from organic petrology, gas adsorption, and mercury intrusion, AAPG Bull. 97(10) (2013) 1621-1643.

22. R. Chen and S. Sharma, Role of alternating redox conditions in the formation of organic-rich interval in the middle Devonian Marcellus shale, Appalachian basin, USA, Palaeogeogr. Palaeoecol. 446 (2016) 85-97.

23. X. Y. Gao et al., Analysis of geological effects on methane adsorption capacity of continental shale: A case study of the Jurassic shale in the Tarim basin, northwestern China, Geol. J. 51(6) (2016) 936-948.

24. X. Tang et al., Shale characteristics in the southeastern Ordos basin, China: Implications for hydrocarbon accumulation conditions and the potential of continental shales, Int. J. Coal Geol. s128-129(3) (2014) 32-46.

25. S. Jiang et al., Comparison of marine, transitional, and lacustrine shales: A case study from the Sichuan basin in China, J. Petrol. Sci. Eng. 150 (2016) 334347.

26. Y. H. Shen et al., Water imbibition of shale and its potential influence on shale gas recovery - A comparative study of marine and continental shale formations, J. Nat. Gas Sci. Eng. 35 (2016) 11211128.

27. K. Kaneko et al., Surface fractal dimension of microporous carbon fibres by nitrogen adsorption, $J$. Chem. Soc. Faraday Trans. 87(1) (1991) 179-184.

28. A. L. Ahmad and N. N. Mustafa, Pore surface fractal analysis of palladium-alumina ceramic membrane using Frenkel-Halsey-Hill (FHH) model, J. Colloid Interf. Sci. 301(2) (2006) 575-584.

29. Y. B. Yao et al., Fractal characterization of adsorption-pores of coals from North China: An investigation on $\mathrm{CH}_{4}$ adsorption capacity of coals, Int. J. Coal Geol. 73(1) (2008) 27-42.

30. J. Liu et al., Comparison of three key marine shale reservoirs in the southeastern margin of the Sichuan basin, SW China, Minerals 7 (2017) 179.

31. L. Chen et al., Sequence stratigraphy and its application in marine shale gas exploration: A case study 
of the Lower Silurian Longmaxi formation in the Jiaoshiba shale gas field and its adjacent area in Southeast Sichuan Basin, SW China, J. Nat. Gas Sci. Eng. 27 (2015) 410-423.

32. J. J. Zhao et al., Applying sedimentary geochemical proxies for paleoenvironment interpretation of organic-rich shale deposition in the Sichuan basin, China, Int. J. Coal Geol. 163 (2016) 52-71.

33. B. D. Ritts, Lower-middle Jurassic nonmarine source rocks and petroleum systems of the northern Qaidam basin, northwest China, AAPG Bull. 83(12) (1999) 1980-2005.

34. T. X. Guo et al., Favorable area selection and resource potential of the Middle Jurassic strata on the southern Altyn Tagh Mountains, NW China, China J. Geol. 52(1) (2017) 93-105.

35. D. Avnir and M. Jaroniec, An isotherm equation for adsorption on fractal surfaces of heterogeneous porous materials, Langmuir 5(6) (1989) 1431-1433.

36. N. R. Khalili, M. Pan and G. Sand,, Determination of fractal dimensions of solid carbons from gas and liquid phase adsorption isotherms, Carbon $\mathbf{3 8}(4)$ (2000) 573-588.

37. D. Avnir, D. Farin and P. Pfeifer, Molecular fractal surfaces, Nature 308 (1984) 261-263.

38. H. Qi, J. Ma and P. Wong, Adsorption isotherms of fractal surfaces, Colloids Surf. A: Physicochem. Eng. Asp. 206 (2002) 401-407.

39. Y. Yin, Adsorption isotherm on fractally porous materials, Langmuir 7(2) (1991) 216-217.

40. S. H. Zhang et al., The characters of coal beds micropores and its influence factors in the eastern Margin of Ordos basin, Acta Geol. Sin. 10 (2008) 1341-1349.

41. P. Pfeifer and D. Avnir, Chemistry nonintegral dimensions between two and three, J. Phys. Chem. 79 (1983) 3369-3558.

42. G. R. L. Chalmers, D. J. K. Ross and R. M. Bustin, Geological controls on matrix permeability of Devonian gas shales in the Horn River and Liard basins, northeastern British Columbia, Canada, Int. J. Coal Geol. 103 (2012) 120-131.

43. H. Tian et al., A preliminary study on the pore characterization of Lower Silurian black shales in the Chuandong Thrust Fold Belt, southwestern China using low pressure $\mathrm{N}_{2}$ adsorption and FE-SEM methods, Mar. Petrol. Geol. 48 (2013) 8-19.

44. W. T. Zeng et al., The gas content of continental Yanchang shale and it main controlling factors: A case study of Liuping-171 well Ordos basin, Nat. Gas Geosci. 25 (2014) 291-301.
45. S. J. Gregg and K. S. W. Sing, Adsorption, Surface Area and Porosity, 2nd edn. (Academic Press, New York, 1982), p. 87.

46. K. S. W. Sing et al., Reporting physisorption data for gas/solid systems with special reference to the determination of surface area and porosity, Pure Appl. Chem. 57 (1985) 603-619.

47. J. C. Groen, L. A. A. Peffer and J. Perez-Ramírez, Pore size determination in modified micro- and mesoporous materials. Pitfalls and limitations in gas adsorption data analysis, Micropor. Mesopor. Mat. 60(1-3) (2003) 1-17.

48. T. T. Cao et al., Characterization of pore structure and fractal dimension of Paleozoic shales from the northeastern Sichuan basin, China, J. Nat. Gas Sci. Eng. 35 (2016) 882-895.

49. J. G. Hu, S. H. Tang and S. H. Zhang, Investigation of pore structure and fractal characteristics of the lower Silurian Longmaxi shales in western Hunan and Hubei provinces in China, J. Nat. Gas Sci. Eng. 28(6) (2016) 522-535.

50. M. Wang et al., Fractal characteristics of upper Cretaceous lacustrine shale from the Songliao basin, NE China, Mar. Petrol. Geol. 67 (2015) 144-153.

51. X. H. Shao et al., Pore structure and fractal characteristics of organic-rich shales: A case study of the lower Silurian Longmaxi shales in the Sichuan basin, SW China, Mar. Petrol. Geol. 80 (2017) 192-202.

52. J. Q. Tan et al., Shale gas potential of the major marine shale formations in the upper Yangtze platform, South China, Part III: Mineralogical, lithofacial, petrophysical, and rock mechanical properties, Fuel 129(4) (2014) 204-218.

53. R. G. Loucks et al., Spectrum of pore types and networks in mudrocks and a descriptive classification for matrix-related mudrock pores, AAPG Bull. 96 (2012) 1071-1098.

54. G. R. L. Chalmers and R. M. Bustin, Lower Cretaceous gas shales in northeastern British Columbia. Part I: Geological controls on methane sorption capacity, Bull. Can. Petrol. Geol. 56 (2008) 1-21.

55. G. R. L. Chalmers, R. M. Bustin and I. M. Power, Characterization of gas shale pore systems by porosimetry, pycnometry, surface area, and field emission scanning electron/transmission electron microscopy image analyses: Examples from the Barnett, Woodford, Haynesville, Marcellus, and Doig units, AAPG Bull. 96 (2012) 1099-119.

56. L. Zhou et al., Physisorption of gases on porous solids at above-critical temperatures, Prog. Chem. 11(3) (1999) 221-226. 